Revista Iberoamericana, Vol. LXVII, Núm. 196, Julio-Setiembre 2001, 557-569

\title{
TINÍSIMA, DE ELENA PONIATOWSKA: SUBJETIVIDAD, REPRESENTACION Y NARRATIVA ACTUAL LATINOAMERICANA
}

\author{
POR \\ Gisela Kozak Rovero \\ Universidad Central de Venezuela
}

ApRovecharSE DE LA BIOGRAFÍA TRAICIONÁNDOLA: TINÍSIMA, UN RECORRIDO POR LAS UTOPÍAS DEL SIGLO XX

Tinísima, ${ }^{1}$ una novela de seiscientas sesenta páginas, posee un lejano origen en un guión cinematográfico jamás llevado a la pantalla. En los agradecimientos al final del texto, nos encontramos con una lista de personajes entrevistados, con la mención a los diarios del fotógrafo estadounidense Edward Weston, al texto del revolucionario italiano Vittorio Vidali sobre Tina Modotti, así como a varios periódicos y textos testimoniales e históricos. Del primer arqueo informativo salió una mirada previa sobre el personaje, en la cual tenían un papel central los testimonios sobre la fotógrafa italiana, una mirada que por más imaginativa que fuese tenía que responder a las inflexibles exigencias del lenguaje cinematográfico, a la necesaria síntesis de un género constituido por imágenes y con requerimientos técnicos ineludibles.

Abortado el proyecto fílmico, Poniatowska continúa su investigación asumiendo los roles triples o dobles que la caracterizan: novelista, periodista, biógrafa. La mirada se amplía y renueva con multitud de testimonios y referencias hemerográficas y bibliográficas que nos ofrecen una suerte de puesta en escena del cómo se construye un saber histórico o la trayectoria de una vida; interesan las contradicciones, los apoyos y rechazos, los enfrentamientos ideológicos que signaron la existencia de Tina Modotti, la imagen íntima de ella que guardaron sus parejas, los testimonios de artistas y políticos, de historiadores y periodistas de diversas épocas. La biógrafa recoge un saber con, si se me permite un muy discutible término, "fidelidad" — en abierto juego con la "verdad"oficialmente asumida como tal—, la periodista indaga las incitaciones detrás de lo sabido y la novelista construye lo que falta, con intachable verosimilitud: el encuentro de un personaje con la vida trashumante, la aventura, las grietas de las utopías modernas, el amor y la discriminación de la mujer. Tinísima se extiende por centenares de páginas acercando mundos de significación heterogéneos - la historia, la fotografía, los testimonios orales, la biografía, el feminismo, visiones de la prensa de la época, discusiones estéticas y políticas- que se unifican en función de la coherencia interna del mundo ficticio construido. Y tal coherencia desplaza los términos verdad y ficción de su tradicional oposición, en una

${ }^{1}$ Elena Poniatowska. Tinísima. México: ERA, 1992. 
abierta exploración de los límites y convenciones en los que nos movemos cotidianamente respecto al siglo $\mathrm{xx}$.

Y es que el uso de la biografía en Tinísima se corresponde con un proyecto estético que subvierte el género pero también lo aprovecha con inteligencia. El aprovechamiento de las convenciones genéricas tiene que ver con que en Tinísima se juega con el papel de fuente histórica de la biografía, su relación con la investigación erudita e, incluso, sus pretensiones divulgativas y su parecido con la novela que la hacen más apetecible que las reflexiones del Historiador con mayúsculas. No es un relato sobre la vida de una fotógrafa, en su paso por grandes conflictos mundiales cuyo origen proviene de las sociedades patriarcales, lo cual la adscribiría a una visión tradicional de la forma biográfica como intento de unidad y coherencia novelescas. Es un texto narrativo sobre un personaje histórico reconocido en medio de personajes históricos importantísimos, y esta elección no es inocente.

Una visión cínica diría resueltamente que se trata de una sabia opción de mercadeo, lo cual no tiene por qué ser necesariamente malo. Me inclino por una perspectiva más elaborada: esferas discursivas asumidas como distintas — historia, biografía, novela — se conjugan con el fin de que la ficción modifique el saber aceptado sobre la vida de una mujer, cuya trayectoria es emblemática de una época, y sobre esta misma época. Esta modificación es posible gracias a que la ficción se libera de la servidumbre respecto a la esfera de lo "real” (Garrido Domínguez 16). De este modo puede utilizarse el sentido más clásico de la biografía — la representación de una vida con trascendencia histórica— con intenciones de expresar una visión alternativa del mundo. A diferencia de Magdalena Perkowska-Álvarez, pienso que la trasgresión no se concreta sólo a transformar las premisas del género - la estructura temporal propia de la crónica, el sujeto como identidad acabada, las convenciones del realismo en cuanto modo de representación, las conexiones con la perspectiva patriarcal (201-02) — aunque todo esto es importantísimo, sino que se amplía en el sentido de aprovechar las características tradicionales de la biografía y su situación de género limítrofe y sacarla, en tanto texto que alude a personajes de carne y hueso, del dominio del discurso histórico para ubicarla en el terreno de la ficción, enfrentando así las dicotomías verdad-verosimilitud, novela-historia, biografía-ficción, y concepciones reductoras relativas a los llamados géneros “menores”, ya sea en el terreno de la literatura o del discurso historiográfico.

Comenzaré el análisis de la subversión del género biográfico mismo, presentando la novela al estilo de una reseña de contraportada.

Tina Modotti, inmigrante harapienta y miserable, oriunda de Udine, un pueblo italiano en el que había trabajado como obrera siendo casi una niña, viaja de adolescente a Estados Unidos en barco, testigo y parte de las migraciones masivas que tanto han tenido que ver con el norte, centro y sur de América. Luego se convierte en la joven fascinada con la posibilidad de un éxito veloz, propio del “american dream”, participa en películas mudas, descubre la vida de los artistas de vanguardia, recibe la adoración de los hombres, en particular la de su primer marido, Roubaix de L'Abrie Richey; y conoce a su segundo amor, amén de maestro de fotografía, Edward Weston. Posteriormente, huye de los rigores de la cultura anglosajona a México; se convierte en artista, en admiradora y modelo de Diego Rivera, y se adscribe a las utopías de progreso y revolución socialista mundial. Se 
une al pintor Xavier Guerrero y comienza a explorar las tradiciones y pasiones antimodernas del México posrevolucionario, lanzado hacia el futuro con toda su carga de atavismo. En este país se convierte en una diva, rodeada por una “pléyade” de artistas y personalidades públicas, y se hace famosa como fotógrafa. Conoce al revolucionario cubano Julio Antonio Mella, con el que vive una historia amorosa que está de algún modo presente en todo el texto, y que transcurre poco antes de que él fuese asesinado por sus enemigos políticos. Finalmente, es juzgada por conspiradora y expulsada de México por extranjera. Después de vagar una temporada en un barco que hace las veces de cárcel, comienza su periplo europeo, escenario de su relación con el revolucionario italiano Vittorio Vidali, y llega a transformarse en una suerte de Mata Hari, aunque bastante puritana, del espionaje soviético, y, tiempo después, en la militante sacrificada y humilde que sirve a los republicanos españoles como enfermera, cocinera y, alguna vez, traductora, olvidada de que fue en el pasado una fotógrafa talentosísima y original, tal como lo evidencian las frecuentes alusiones en la novela y las fotos que ilustran el texto. Prematuramente envejecida y aplastada por las decepciones y fracasos de su paso por la Alemania prenazi, La Unión Soviética y la Guerra Civil española, vuelve a México acompañada por Vidali y muere en este país a los cuarenta y cuatro años.

Vista así la novela se construye en términos de la totalidad de una vida, tal como corresponde a cualquier biografía convencional. De una vida paradigmática y apasionante —que recorre los grandes escenarios de las revoluciones políticas, artísticas y culturales de la primera mitad del siglo xx-, en la que el amor es transformación radical de la existencia, es conocer el mundo y cambiar con él, dada la personalidad de los amantes, en su mayoría hombres importante en la vida artística o política. En suma es una de esas vidas pasto de grandes producciones cinematográficas, en las que los espectadores del presente nos lamentamos de las iniquidades de un pasado que no entendió quiénes eran sus verdaderos protagonistas. Mas Tinísima no cedió tan fácilmente a esta tentación, no sucumbió a la sugerente trampa mimética de la fidelidad a los registros de la historia y del fasto de las grandes descripciones. Magdalena Perkowska-Álvarez (207-12) registra con minuciosa atención los quiebres, encuentros, desencuentros, elisiones y pausas que refutan la estructura temporal de crónica que subyace en toda biografía tradicional: las fechas que encabezan los “capítulos” abarcan desde momentos hasta semanas y meses; las fotografías que los anteceden revelan, por analogía y dado su carácter de recorte de lo "real”, que no es posible pensar en una continuidad temporal sin mediación de una selección interesada, y que en los vacíos dejados por tal selección caben todos los elementos e interpretaciones posibles. La novela comienza con la muerte de Julio Antonio Mella, su historia personal, su romance con Tina, el enjuiciamiento de ésta como sospechosa de participar en la muerte de su amante, su absolución y su ida a Juchiteca. Al llegar a este punto, se produce un giro en la narración: Tina ha estado contando su historia en una suerte de relato autobiográfico en tercera persona, por medio del modo narrativo indirecto. Las trasgresiones no terminan aquí: la voz narrativa predominante es la tercera persona omnisciente que domina con poder divino el relato, recurso realista propio también de las aventuras biográficas sutilmente subvertido a través del juego con las focalizaciones: las distancias narrativas aumentan y se reducen permanentemente, abriéndonos los ojos respecto a cualquier duda sobre la naturaleza del texto, que se 
reconoce sin remilgos como "novela” en la portada misma. Esas distancias cuestionan igualmente las pretensiones de objetividad o infalibilidad del discurso histórico, pues en lugar del uso en el relato del tiempo pasado como evidencia de la imposibilidad de modificar la historia, se impone resueltamente el presente, prueba de una voluntad de transformar lo aceptado en aras de un nuevo conocimiento obtenible por la vía de la ficción literaria.

Tiempo, modo y juegos del narrador evidencian el cuidadoso trabajo de reelaboración de la biografía en cuanto género, con toda la carga ideológicamente revulsiva que implica el irónico y lúdico rechazo de cualquier pretensión de objetividad que imponga una versión unívoca del vivir histórico y personal. Pero, además, las distancias narrativas en Tinísima, afectivas, intelectuales, morales, espacio-temporales se conjugan para presentarnos las fisuras y contradicciones que erosionaron hasta volver polvo las grandes utopías de la modernidad. El narrador se metamorfosea en los sentidos, la piel, los recuerdos, la sensibilidad y los anhelos de Tina, entregada a su aprendizaje erótico y artístico, enamorada de los colores, sabores y olores de México, de la contradictoria pulsión modernizante que sacudía sus cimientos. Ese mismo narrador se aleja sin complejos cuando Tina, fanática de la militancia comunista, rechaza, en una suerte de paradójico misticismo político, a sus antiguos amigos por decadentes. A Diego Rivera por traidor de la causa revolucionaria, al poeta Maiakovsky, por suicidarse, al cineasta Sergei Einsenstein, por su individualismo pequeñoburgués, al revolucionario Lev Kamenev adalid de la Revolución Bolchevique_ por no someterse a los dictámenes del estalinismo, y a los republicanos no comunistas españoles, por no plegarse al dogmatismo del partido. Igualmente, pone en evidencia la ceguera de Tina ante las contradicciones flagrantes del socialismo soviético, de las organizaciones revolucionarias que utilizaban con impunidad a sus militantes y que marginaban a las mujeres de los proyectos de transformación mexicanos, de una perspectiva histórica que ignoraba la pluralidad y simultaneidad de registros propios del vivir humano. Y de este juego de distancias se desprende una visión desilusionada sobre las grandes utopías contemporáneas, impregnada de un toque nostálgico, magistralmente logrado en la crónica apretada e intensa de la Guerra Civil Española, ilustrada con las fotos de Robert Cappa y Gerda Taro, en el relato del entusiasmo inicial que marcó la gesta educativa de José Vasconcelos en México, o en el saludo de los cubanos a Tina en su breve paso por las costas de la isla luego de la muerte de Mella.

Pero, ¿qué nos sugiere Tinísima, en su tratamiento de la biografía, respecto a los debates sobre la representación, el feminismo y la narrativa latinoamericana actual? Al insistir en representar a Tina Modotti, un personaje femenino que alude a sujetos con existencia histórica, la novela nos habla de una reescritura de la(s) historia(s) desde una mirada que le concede voz a sectores otrora acallados. Pero no se trata sólo de conceder una voz. Se trata de que esa voz sea vista, en tanto representación, no en el sentido de "sustitución mimética” — representación y objeto representado-(Derrida 82), sino como confluencia de “discursos monológicos” y “retextualización” de los mismos (Alarcón 144). Es en este sentido que, como ya dije en otras páginas, esta novela modifica la visión ofrecida por los diversos discursos políticos, históricos, artísticos y sociales al conferirles una significación novedosa, distinta (Lewis 8). Las grandes gestas revolucionarias, la mitificación de personajes femeninos y masculinos, la valoración socio-cultural de un 
personaje con existencia real y de su obra, los conflictos de la condición femenina ante el vivir en sociedad son revisados en Tinísima, a partir de conjugar el conocimiento existente sobre una fotógrafa y revolucionaria conocida y la exploración propia de la escritura en la construcción de su campo de referencia interno (Harshaw 129), que es distinto a los referentes "reales" y no tiene por qué obedecer a los imperativos de una perspectiva ideológica previa. El uso de la forma biográfica y el trasunto histórico del texto nos hablan entonces de una visión de la representación literaria que asume que, efectivamente, lo representado no es un contenido independiente del lenguaje que lo evoca (Derrida 87), pues el uso mismo de géneros literarios, tan marcados ideológica y estéticamente, imprime un sesgo particular a la visión de mundo que se desprende del texto: es una iniciativa estética "realista" — en el sentido de utilizar determinados recursos para causar así una fuerte ilusión de "realidad”- perfectamente consciente de que todas sus tácticas son un juego propio de la ficción (por eso Tinísima subvierte el género biográfico y se libera de muchas de sus limitaciones estético-ideológicas). Pero, al mismo tiempo, dicho juego propio de la ficción reivindica —al conjugar dimensiones discursivas distintas y darle nuevos sentidos a sus enunciados - "una exterioridad al discurso" (Richard 735), es decir, las condiciones económicas, sociales, individuales y culturales que toman cuerpo y cara en el entramado discursivo de la sociedad. ${ }^{2}$

La forma biográfica en este caso da por sentado la importancia de la subjetividad como punto nodal para la comprensión del vivir histórico y social al centrarse en el protagonismo absoluto de un personaje. Por ello, Tinísima nos recuerda las potencialidades de la literatura en tanto posibilidad de conocimiento y transformación de la cultura, en tanto discurso capaz de evidenciar las “estructuras del sentir”, es decir, la vivencia misma del sujeto en el mundo, relacionada con "las creencias sistemática y formalmente sostenidas” (William 154-55). El abismo entre lo pensado y lo hecho, las propias apetencias y lo que se espera de nosotros, la necesidad de amar y de ser libre, la estética y la militancia, el origen social y el estilo de vida adulto, las ideas y su realización, las utopías y lo real, la condición femenina y la masculina, tienen en esta novela un lugar privilegiado. Y es que las formas y convenciones mismas de un texto literario indican con frecuencia que se está generando una nueva estructura del sentir: la incontestable presencia del debate feminista en las últimas décadas influye la visión de las escritoras sobre su quehacer narrativo, de allí el interés por formas literarias que iluminen la subjetividad en sus conflictos y quehacer en el mundo.

Desde luego, este interés no es causa de unanimidad crítica en ningún sentido. Tinísima, ciertamente, se apoya en estrategias narrativas realistas las cuales pueden ser contempladas de manera contradictoria: como una muestra de la agonizante creatividad que empantana nuestros días, la cual persigue formas de escritura preteridas (Britto García 64); como una respuesta de los escritores que empiezan a publicar en los setenta frente a las audacias del "boom” (Skármeta 58); o, finalmente, como manifestación de un proceso de revisión de géneros como la biografía, en este caso, a partir de la necesidad de formular un replanteamiento radical sobre la mujer en tanto sujeto histórico desde la ficción literaria

\footnotetext{
${ }^{2}$ Otras escritoras reivindican esa exterioridad por vías distintas a las de Poniatowska: Diamela Eltit, Carmen Boullosa, entre otras. No intento en este trabajo hacer una apología de las estrategias "realistas".
} 
(Russotto 105).Me inclino por las dos últimas opciones, y coincido con George Yúdice (122-23) cuando al caracterizar las búsquedas narrativas de las últimas décadas arguye que, de vuelta de la búsqueda de novedad propiciada por los escritores del "boom”, los novelistas asumen una actitud de apertura y se han dedicado a la revisión de géneros abandonados por las distintas vanguardias de la contemporaneidad: Tinísima es un excelente ejemplo de ello y de la intersección entre las búsquedas de las escritoras y del feminismo con las pulsiones culturales de los últimos tiempos, que influyen también, por supuesto, sobre los narradores masculinos.

Sujeto: ¿marca lingüística o marca en la piel? Tinísima, aventura y contemplación. No me imagino una posible lectura de Tinísima que olvidara la dimensión humana y existencial de su protagonista, de ese sujeto textual ${ }^{3}$ que toma su cara más acabada en el personaje de Tina, y que nos lleva y nos trae entre las dimensiones históricas, subjetivas, amorosas, políticas, femeninas y feministas de un texto construido como biografía, como relato de aventuras en clave de mujer. El periplo vital de la fotógrafa y revolucionaria italiana da cuenta de la índole proteica de la identidad, en tanto conjunto de posiciones de sujeto (Smith 39), articuladas a partir del cuerpo y la condición del personaje, protagonista de un mundo de proporciones épicas, relatado desde la ambigüedad de una voz narrativa que usa la omnisciencia para negarla irónicamente, pues nos habla no desde un poder divino sobre la materia narrada, sino desde la privacidad y la intimidad de una mujer que se transforma y modifica en función de las experiencias vividas.

En este sentido es preciso señalar la importancia de las ilustraciones —-fotografías, reproducciones de dibujos y pinturas — en cuanto a la imagen del personaje. Ciertamente, los dibujos de su primer marido Roubaix de L’Abrie Richey, las pinturas de Diego Rivera, las fotografías en las que es retratada, nos muestran una Tina vista como mujer en flor, como encarnación de la feminidad, como amante, como pareja. Muy distinta es la situación cuando Tina es la fotógrafa que da su visión del mundo. Las fotos nos hablan en tanto posibilidades de significación que articulan posiciones de sujeto, y tales posiciones en el caso de Tina toman forma en el delicado trabajo narrativo por medio del cual el personaje se modifica en la convergencia de lo público y lo privado, lo histórico y lo personal, lo individual y lo colectivo. Cuando he hablado del aire épico de Tinísima, de su parentesco no sólo con la biografía sino con las grandes novelas realistas y los relatos de viaje, he intentado referirme a cómo la situación femenina no es vista desde la intimidad y lo privado exclusivamente. En Tinísima se conjuga la visión intimista con una visión de mundo a gran

\footnotetext{
${ }^{3}$ El personaje es la instancia de intermediación discursiva entre el sujeto de enunciación y el sujeto de la lectura, es objeto del diálogo implícito en el acto de narrar (Kristeva 113), y, a la vez, sujeto y agente del acontecer novelesco. El proceso narrativo confluye, desde esta perspectiva, en la constitución del sujeto textual, cuya evidencia más inmediata es el personaje, aun cuando es irreductible a éste pues implica todos los elementos participantes en la constitución del relato. La profunda densidad y complejidad significativa propia del sujeto textual —en el que convergen instancias semiótico-discursivas contradictorias, relacionadas con la creación y recepción del texto y elaboradas y recreadas a fin de ampliar el horizonte de lo "real” — es la razón por la cual los lectores de literatura — por lo menos los no especialistas - disfrutan de la dimensión humana y cultural de la representación, del fruto de un proceso de construcción de un mundo ficcional con características propias.
} 
escala, lo cual, sin duda, es digno de tomar en cuenta, dada la tendencia, en muchas novelas escritas por mujeres, de privilegiar el espacio de la interioridad, lo confesional, lo privado.

Dadas estas dos visiones, un aspecto fundamental del desarrollo del personaje es su interés por tomar parte en un contexto artístico, histórico y político en el que la mujer participa con roles secundarios. Y la manera en que, de algún modo, logra darle un rostro a ese interés, a ese deseo, es a través de la búsqueda de modelos que se conviertan en mediadores de éste, en tanto dignos de imitación (Girard 7). Tina oscila entre un individualismo que no se da tregua y un ansia por fundirse en el espíritu gregario, las dos caras de una misma preocupación por el "otro" (Girard 16), que en su caso toma forma a través de un tópico presente en mucha de la narrativa escrita por mujeres: el hombre como intermediario en el conocimiento y conquista de un mundo hecho más a la medida de él que a la medida de la mujer. En la imitación de sus modelos vamos encontrando la línea que da coherencia a la trayectoria vital de la protagonista, en el peor y en el mejor sentido. Y es que Tina se mueve siempre en un sutil, o abierto, juego de traiciones respecto a sus mediadores: su primer gran mediador es su padre, socialista de Udine, al que siente que traiciona cuando se entrega abiertamente a sus sentimientos y sentidos. Pero el socialista de Udine triunfa de nuevo cuando Tina se distancia despectivamente de su pasado, de Edward Weston su maestro de fotografía entregado a la estética y al disfrute de la vida, para quedarse con el muralista Xavier Guerrero. Guerrero en tanto pintor, hombre y militante, es un paradigma de un puritanismo comunista que Tina ve con temor y reverencia, sintiéndose indigna ante la entrega revolucionaria de su amante. Se unirá posteriormente a Julio Antonio Mella, parte fundamental de ese aprendizaje en México que llevará a Tina a la mayor expresión de su personalidad. Mella estará presente siempre en sus sueños y en su vida, más allá de su muerte, como el hombre que encarnó su mejor momento como amante, artista y revolucionaria. Sin embargo, también Mella es alcanzado por las traiciones de Tina, quien olvida la dimensión humana del militante para entregarse al realismo político de Vittorio Vidali. Lo que Tina contempla como fracaso, para Vidali es visto como un paso más dentro de la revolución mundial; lo que para Tina es horror, para Vidali es parte de la excitante atmósfera de pólvora y confrontación, parte de la fascinación que puede ejercer la guerra sobre los hombres.

Pero sería injusto y esquemático pensar que Tina es sólo una víctima. Sus traiciones respecto a los demás y respecto a sus propias ambiciones e impulsos parten de decisiones propias, las cuales responden a un juego de tensiones entre la protagonista como individuo y las sociedades en las que le toca vivir, entre su deseo de emancipación y su fascinación por las reglas del mundo masculino. Dejar la fotografía por el activismo político es una opción que hasta sus compañeros revolucionarios le reclaman. Vidali, en medio de su incapacidad para entender a Tina, la Stásova, su jefe cuando recorría Europa en su rol de espía, sus conocidos en Alemania, la impelen a que tome la cámara. La tensión entre obra y manifiesto, política y estética, adelantos tecnológicos y búsqueda artística, senderos individuales y necesidades colectivas, fue el sino de los numerosos artistas e intelectuales que han participado en movimientos revolucionarios en este siglo. Tina no es la excepción, pero a diferencia de muchos de ellos no encontró una posibilidad de expresión personal en medio de una situación complejísima. Gerda Taro y Robert Cappa, grandes fotógrafos, sí la encontraron, y su participación en la Guerra Civil Española fue en cuanto tales. Tina, 
en suma, no ve en el documento político una posibilidad artística real y entonces abandona el arte por la militancia, sin detenerse en sus propios impulsos y necesidades, suerte de mártir contemporánea, de mujer entregada voluntariamente al sacrificio.

Y es que la perspectiva narrativa sobre el personaje está enfocada, retomando todo lo dicho en páginas precedentes, hacia la esencial insatisfacción que agobia a Tina en todos los momentos de su vida. Esta insatisfacción es el punto de partida para entender las variaciones de su comportamiento, sus errores, aciertos y contradicciones, y la adecuada representación de éstos en el texto, y para entender, igualmente, la particular inserción del sujeto femenino en un campo minado por la omnipresencia del patriarcado. La representación emerge entonces del conflicto mismo entre la historia y la actividad humana, entre el yo y el otro (Salabert 31). El conflicto es aquí más agudo por cuanto que ese conflicto humano yo-otro, responde en el caso de la mujer, y en particular de este personaje femenino de la primera mitad del siglo xx, a una tensión entre su propia visión crítica sobre su entorno y sus sentimientos amorosos hacia los hombres que tuvo cerca, agentes, voluntarios o no, de una visión que condena a la mujer al rol de comparsa. Sin embargo, y a diferencia de tantas novelas sobre conflictos semejantes, la habilidad de Poniatowska para delinear personajes masculinos dotados de gran plasticidad, impide una visión unilateral del asunto: ${ }^{4}$ Tina aprende de sus amores y ellos al mismo tiempo la marginan y la aúpan desde el punto de vista erótico, político y artístico; sufre por sus amores, pero sus grandes momentos tienen que ver con ellos en más de un sentido; es una mujer enfrentada a un mundo de hombres pero, a su manera, logra ser una mujer reconocida, emancipada de muchas de las limitaciones de sus contemporáneas, aunque el precio a pagar fuese el ser juzgada con temible encono y dureza. Atribulada por sus deseos, Tina no podía ser una fotógrafa al estilo de Edward Weston, o un líder comunista al estilo de Julio Antonio Mella, pero queda para la historia como ellos, y se entrega a sus causas con la misma fortaleza, aunque a costa de sacrificarse a sí misma.

Tinísima es, en suma, un intento de revisión de las grandes utopías contemporáneas desde la condición femenina, y por ello manifiesta, en tanto escritura literaria, una voluntad de contemplar el mundo en toda la complejidad de las relaciones intersubjetivas. Nos habla, por tanto, de sujetos históricos, irreductibles a cualquier definición posestructuralista que los reduzca a simple marca lingüística. ${ }^{5}$ Tina es caracterizada de

${ }^{4}$ Coincido con Nelly Richard (742) sobre la necesidad de un discurso desde la mujer que se asuma como metáfora, nacida de un profundo movimiento dialéctico, de los más diversos sistemas de oposiciones, y que ponga de relieve una visión de mundo dinámica y cambiante, más allá de cualquier militancia y cualquier visión "esencialista” sobre la condición femenina.

${ }^{5}$ Cito a Julio Ortega: "Todavía hasta ayer algunos teóricos modernistas y posmodernistas (o estructuralistas o posestructuralistas, de acuerdo con la identidad que asuman), creyeron que la identidad era poco menos que irrelevante. Unos por depender de la supuesta universalidad del cartesianismo, otros por creer que la subjetividad es un mito. Ambos, así, por responder a las sobrecodificaciones positivistas o a las disoluciones irracionalistas, según el caso, de sus propias posiciones del discurso como si determinaran la naturaleza misma del sujeto universal. Siempre he creído que si Barthes hubiese leído a José María Arguedas o a Juan Rulfo no habría decretado la "muerte del autor", pues hubiese encontrado que la autoría era otro signo de la subjetividad deseante y subvertora. Si Foucault hubiese seguido su exploración de Borges más allá de la arbitrariedad de toda clasificación, podría haber visto que el sujeto no es sólo creado por su posición en el discurso 
acuerdo con todas las marcas de identidad posibles: es mujer e italiana, de origen pobre, heterosexual, militante política, artista, mujer trashumante que cambia de lugar, de ideas, de hombre, joven, adulta y vieja muy prematura, sensual y espartana, políglota, atravesada por todas las culturas por las que ha pasado. En consecuencia, la concepción del sujeto que se desprende de la construcción de la protagonista y de otros personajes, es que se trata de un ente cambiante que posee capacidad negadora frente a lo histórico y busca su identidad, en relación con el mundo y con los otros (Castoriadis 106).

De dicha búsqueda de identidad se desprende la visión feminista que impregna el texto. En el caso de Tinísima se asume que la mujer no puede reducirse a un mundo significante y vital propio que abra el paso a un monologismo análogo al del patriarcado (Richard 741): Tina está en permanente diálogo con un entorno en el cual su subalteridad esencial imprime a ese diálogo una particular inserción, una mirada oblícua, una alteración dentro de un contexto demasiado de acuerdo consigo mismo en lo que a la mujer se refiere. Es un personaje cuya sola presencia y trayectoria cuestiona los valores machistas, aun cuando en diversos momentos haya comulgado con esos valores.

Por último, Tinísima asume como suyas distintas, y contrapuestas, polémicas a partir de poder jugar eficazmente con la estructura narrativa y la construcción de personajes; en otras palabras, a partir de su condición de texto novelesco. Y desde esta condición asume sus relaciones con tendencias de la narrativa continental de las últimas décadas. El personaje protagonista se perfila a partir de la intrahistoria y de la rebelión contra el poder como presencia constante en el vivir cotidiano y social, erigiéndose en una voz definida por su marginalidad, rasgos que han sido considerados característicos de la vagamente llamada narrativa del "posboom”(Rama 187). Y dichos rasgos obedecen a una visión de nuestro continente que privilegia un tipo de indagación histórica que pasa por el tamiz del existir diario, de la conducta individual, del vivir desde la pequeña tragedia personal los grandes procesos colectivos. Este tipo de narrativa implica, pues, una ruptura con las instancias míticas, arquetípicas, de temporalidad circular y alto vuelo filosófico o antropológico, propias de grandes autores, ya canonizados, de otras épocas como Juan Rulfo, Gabriel García Márquez, João Guimarães Rosa, Alejo Carpentier o José Lezama Lima, ${ }^{6}$ ruptura necesaria dada la profunda e intensa discusión sobre la(s) modernidad(es) continental(es) que se ha llevado, y se lleva, a cabo en América Latina. Se han modificado las visiones sobre nuestro acontecer y sobre las finalidades y caminos de nuestra novelística: muchos fracasos políticos-sociales y culturales y brutales realidades económicas, dan sentido a una literatura menos ufana de sus capacidades de nombrar y transformar el mundo y más interesada en mirar de frente las razones de tantas derrotas históricas.

El autor ha muerto, viva el autor (el sujeto histórico-cultural y sus huellas en el enunciado). ${ }^{7}$

sino desde los cortes de la intradiscursividad, allí donde la identidad borgiana es un proyecto de escritura radical del "mundo" sobrecodificado. Y, en fin, si Lyotard se hubiese encontrado con José Lezama Lima...no se habría resignado a la idea de que el sujeto carece de sustancia. (20-21)

${ }^{6}$ Esta afirmación no puede interpretarse como un cuestionamiento a estos autores; se trata de un simple intento de diferenciación.

${ }^{7}$ Tomando en cuenta la discusión sobre el sujeto, podemos desplazarnos desde la noción de muerte del autor —en el conocido sentido foucaltiano (56) de la desaparición de sus huellas en el 
En este apartado plantearé las huellas -o "autoinscripciones”- del sujeto históricocultural en el enunciado visto como "escritura". La escritura como intermediaria entre dicho sujeto histórico-cultural (en este caso la escritora Elena Poniatowska) y la historia, constituye una posibilidad, en su naturaleza de propuesta estética, de reflexión sobre lo colectivo y lo individual (Trin T. Minh-ha citada por Alarcón 122). Me interesa entonces destacar la manera en que el proyecto narrativo global de Poniatowska, y su condición de mujer, escritora, latinoamericana y feminista, han impreso sus huellas en Tinísima.

En su dimensión de novelista — Hasta no verte Jesús mío (1970), Querido Diego, te abraza Quiela (1978), La flor de lis (1988), Tinísima (1992), Paseo de la Reforma (1996) - , cuentista, periodista y biógrafa, Elena Poniatowska reafirma en su proyecto narrativo la importancia del sujeto en cuanto nudo de confluencias y conflictos socioculturales. Los personajes de la escritora mexicana exhiben una cualidad crítica mucho más auténtica que la de los personajes estereotipados que exaltan cierta visión complaciente de lo femenino, estilo Laura Esquivel. Finalmente, la inserción de una mujer en un mundo de hombres exige pactos, mediaciones, ensayos, errores, rupturas dolorosas, pérdidas y ganancias que en el caso de personajes como Jesusa (Hasta no verte Jesús mío) pobre, sola y vieja, toman un cariz trágico, y, aunque suene paradójico, deliciosamente irreverente, pues si algo no quiere Jesusa es ser vista como víctima. Puede hablarse, entonces, de un feminismo de la apertura y la diversidad, un feminismo capaz de comprender que la condición de la mujer no se reduce sólo a la de la mujer blanca con ciertos privilegios socio-culturales o a su situación en tanto subalterno. Desde esta perspectiva, la importancia

enunciado—, hacia una más ponderada —su exclusión-inclusión en el enunciado en tanto sujeto de la narración metarmofoseado y mediatizado a través de un “él” (sujeto de enunciación, personaje) (Kristeva 113)—, o hacia una más tradicional — los distintos grados de distanciamiento entre el autor y el sujeto de la enunciación (Bajtín 130)—, para reflexionar sobre la relación entre ese sujeto textual del que hablamos en el apartado anterior y el sujeto histórico al que remite. En un momento en que las discusiones sobre estética moderna, —y específicamente sobre la autorreferencialidad literaria cuyo correlato es, precisamente, la muerte del autor-, han dado paso a la necesidad de asumir la pluralidad de codificaciones que constituyen la cultura y de comprender su complejísima interacción, la problemática del autor, no como numen o creador en sentido romántico, sino como sujeto cultural que escribe, vuelve a la palestra con la emergencia de los Estudios Culturales y su interés por los sujetos que enuncian o son enunciados dentro de la producción discursiva como representación y mediación cultural. Concepciones como las de Kristeva y Bajtín continúan teniendo vigencia, al asumir el carácter difícil y complejo que posee el tratar de entender las huellas del sujeto cultural en el enunciado, en tanto que podrían confundirse con contenidos biográficos, y no se trata de esto. El mismo Foucault (56) admite que la escritura moderna es autorreferencial, pero transgrede esa regla y sale de sí misma hacia el exterior porque significa. Y en esa exterioridad estamos los sujetos escritores y lectores vistos como instancias surgidas del conflicto, de los encuentros y desencuentros, entre diversas producciones discursivas definidas a partir de su carácter de representación y mediación cultural. Se trata entonces de entender la presencia del autor como sujeto cultural que escribe y deja sus huellas en el enunciado, partiendo de que, si bien, contemplar la cultura como textualidad, el tantas veces mencionado "giro lingüístico", permite entender la representación simbólico-textual como "sitio de poder y regulación”, expresión de los encuentros y desencuentros entre sujetos e identidades específicas (Hall 279), el vivir histórico e individual es irreductible a dicha metáfora, tal como ha planteado el feminismo (Richard 735 ), o adalides de los Estudios Culturales como Jameson (29), entre otros. 
de la subjetividad en el proceso simbólico de una cultura contradice abiertamente las propuestas que la invalidan como elemento actuante en el mundo. Sólo el escuchar las voces emitidas desde lo subjetivo permite comprender que hay otra historia y otras maneras de contemplar la vida, que detrás de, por ejemplo, la mitificación del hombre artista se esconde, a veces, el silenciamiento de las mujeres artistas, como es el caso de Diego Rivera con Frida Kahlo o con Angelina Beloff (Querido Diego, te abraza Quiela). No es mera casualidad que en las novelas de Poniatowska el personaje femenino central posea un protagonismo definitivo: se trata de ofrecer una ilusión de sujeto a través de la construcción de un personaje que es dibujado en la pluralidad de sus posiciones frente al mundo, en su búsqueda de identidad en tanto personaje-mujer.

La representación de esas posiciones juega un papel fundamental en el proyecto narrativo de Poniatowska y de allí su preferencia por géneros como la entrevista, la carta, la crónica, el testimonio, la biografía, los cuales se relacionan con el espacio de la subjetividad. Pero, tal como dije en páginas anteriores, no se trata, o por lo menos no debería ser visto así, de rescatar un concepto de la representación en tanto "sustitución mimética” o "reflejo” de lo real, para expresar una posición adecuada acerca de la mujer en tanto subalterna. Se trata de entender la heterogeneidad de mundos que cruzan el texto literario, la contradictoria unidad de éstos lograda a través de la modelización estética del lenguaje, la capacidad del(a) escritor(a) para “leer” la cultura de su tiempo y replantearla críticamente. El uso en Poniatowska de géneros como los mencionados los renueva y renueva también nuestras nociones de la historia, de la verdad y de lo verosímil, los ambiguos límites entre los discursos reconocidos convencionalmente como ficción y los que no lo son. No interesa si sus protagonistas — Jesusa, Angelina, Tina— responden o no a los personajes de carne y hueso a los que aluden: interesa la posibilidad de leer y rescribir la cultura poniendo de relieve las “estructuras del sentir”, la grieta abierta entre el “yo” y el "otro”, en la cual las ideologías, los discursos, los sistemas de pensamiento se convierten en inmediatez, experiencia y vivencia.

La novelística de esta escritora mexicana se entronca, pues, con el feminismo, con la crítica feminista, con las polémicas sobre literatura "femenina”, desde su carácter de propuesta narrativa, consciente de los lenguajes y tradiciones que toca y de las que hace uso libremente. El que dichos lenguajes y tradiciones hayan operado dentro de visiones de mundo propias del patriarcado, no les sustrae la carga de cuestionamiento que poseen en el contexto de las escritoras latinoamericanas, en particular, y de los debates estéticos de las últimas décadas en general; han sido transformados por un proceso de escritura que demuestra conciencia estética (lo digo asumiendo todo el lastre ideológico del término), dominio del oficio, penetración cultural, conocimiento, mirada reflexiva y crítica sobre la propia inserción en el mundo como sujeto y como escritora, se participe o no de la idea de una literatura femenina distinta a la masculina. $Y$ es que las escritoras latinoamericanas deben entrar abiertamente en el debate estético y en las polémicas histórico-culturales actuales, más allá de las teorizaciones, generalmente del primer mundo, que dilucidan las características de la literatura femenina o del tipo de mujer o de identidad femenina deseable (Masiello 1996) (Richard 1996). Recordemos, además, que no sólo la crítica está detrás de este tipo de asuntos. El mercado está respaldando una escritura femenina estereotipada — sin vuelo estético y que maneja estereotipos asimilables acerca de la 
mujer - apta para grupos sociales de valores convencionales (Masiello 746). En cambio, la visión feminista en la obra de Poniatowska es un feminismo que, para decirlo con palabras de Nelly Richard, ya citada, incluye lo diverso y lo heterológico en nada despreciable medida: lo privado y lo público, la belleza de la pasión amorosa con la herida de las diferencias genéricas, la subalteridad de la mujer y las consecuencias inevitables de sus propias decisiones, el registro popular y el culto, las descripciones épicas y el calor del erotismo, las maravillas y horrores de las culturas tradicionales y de las sociedades modernizadas, el conocimiento literario e histórico y su subversión.

Para finalizar, resumiré rápidamente las conclusiones de este ensayo. Las tensiones entre feminismo y creación literaria, entre las escritoras y un circuito de creación, difusión y recepción en el que los hombres han mantenido, con diversas maneras y efectos, la hegemonía, entre problemáticas socio-culturales internacionales y la multiplicidad de inserciones subjetivas en ellos, constituyen el punto de partida que explica la solidez de la propuesta narrativa de Poniatowska en Tinísima. Destacan la insistencia en el personaje femenino histórico, el uso de géneros “menores”, una perspectiva de la subjetividad como fuerza histórica, cultural e individual, un feminismo, si se quiere, heterodoxo y una visión de la literatura como práctica simbólico-textual liberadora en tanto ejercicio estético y representación. Estamos, en suma, ante una novela que se coloca en el cruce entre las exigencias del feminismo y los vaivenes culturales de las producciones literarias hechas por mujeres y hombres en general, afectados por las consecuencias de las modernidades latinoamericanas, los rigores y desplazamientos de las estéticas modernas, la búsqueda de caminos para la escritura y los debates sobre la sociedad y el individuo de las últimas décadas.

\section{Bibliografía}

Alarcón, Norma. "La frontera de Andalzúa. La inscripción de una ginocrítica”. Cultura y Tercer Mundo. Nuevas identidades y ciudadanías. Beatriz González, ed. Vol. 2. Caracas: Nueva Sociedad, 1996. 121-46.

Bajtin, Mijaíl. Teoría y estética de la novela. Madrid: Taurus, 1986.

Britto Garcia, Luis. "Literatura y postmodernidades”. Estudios 2 (1993): 61-67.

Castoriadis, Cornelius. La institución imaginaria de la sociedad. Vol. 1. Barcelona: Tusquets, 1983.

Conteris, Hiber. “Formas heterogéneas en la nueva narrativa hispanoamericana”. Texto Crítico 39 (1988): 12-25.

Derrida, Jacques. “Envío”. Deconstrucción en las fronteras de la filosofía: la retirada de la metáfora. Barcelona: Paidós, 1989. 77-122.

Foucault, Michel. “¿Qué es un autor?”. Dialéctica 16 (1984): 51-82.

Garrido Domínguez, Antonio. “Teorías de la ficción literaria: los paradigmas”. Teorías de la ficción literaria. Madrid: Arco/Libros, 1997. 11-40.

Girard, René. Mentira romántica y verdad novelesca. Caracas: Universidad Central de Venezuela, 1963.

Hall, Stuart. “Estudios culturales, dos paradigmas”. Hueso Húmero 19 (1990): 69-80. 
Harshaw, Benjamín. “Ficcionalidad y campos de referencia”. Teorías de la ficción literaria. Madrid: Arco/Libros, 1997. 123-157.

Jameson, Frederic. Ensayos sobre el postmodernismo. Buenos Aires: Ediciones Imago Mundi, 1991.

Kristeva, Julia. El texto de la novela. Madrid: Lumen, 1984.

Lewis, Thomas. “Hacia una teoría del referente literario”. Texto Crítico 26-27 (1983): 331.

Masiello, Francine. "Tráfico de identidades: mujeres, cultura y política de representación en la era neoliberal”. Revista Iberoamericana 176-177 (1996): 745-66.

Ortega, Julio. El principio radical de lo nuevo. Postmodernidad, identidad y novela en América Latina. México: Fondo de Cultura Económica, 1997.

Perkowska-Alvarez, Magdalena. "La negociación del espacio de la mujer en la historia en Tinísima de Elena Poniatowska”. Estudios 10 (1997): 193-315.

Rama, Ángel. “Los contestatarios del poder”. La novela latinoamericana (1920-1980). Bogotá: PROCULTURA, S.A, 1982: 455-94.

Richard, Nelly. “Feminismo, experiencia y representación”. Revista Iberoamericana 176177 (1996): 733-744.

Russotto, Márgara. Tópicos de retórica femenina. Caracas: Monte Ávila, 1990.

Skármeta, Antonio. “Perspectiva de los novísimos”. Hispamérica 28 (1981): 49-64.

Salabert, Pere. “Arte, tiempo, identidad”. Fin de un siglo: las fronteras de la cultura. Rosario: Homo Sapiens Ediciones, 1996: 15-45.

Smith, Paul. Discerning the subject. Minneapolis: University of Minnesotta Press, 1988. William, Raymond. Marxismo y literatura. Barcelona: Península, 1980.

Yúdice, George. “’¿Puede hablarse de postmodernidad en América Latina?”. Revista de Crítica Literaria Latinoamericana 29 (1989): 104-28. 